\title{
Using Molecular Modelling Tools to Understand the Thermodynamic Behaviour of Ionic Liquids
}

\author{
Lourdes F. Vega ${ }^{* 1,2}$, Oriol Vilaseca ${ }^{1,2}$, Edoardo Valente ${ }^{1}$, Jordi S. Andreu ${ }^{1,2}$, \\ Fèlix Llovell1,2, and Rosa M. Marcos ${ }^{3}$ \\ ${ }^{1}$ MATGAS Research Center (Carburos Metálicos/Air Products Group, CSIC, UAB), \\ Campus de la UAB, 08193 Bellaterra, Barcelona \\ 2Institut de Ciència de Materials de Barcelona. Consejo Superior de Investigaciones \\ Científicas. ICMAB-CSIC. Campus de la UAB. 08193 Bellaterra, Barcelona. \\ ${ }^{3}$ Departament d'Enginyeria Mecànica. Escola Tècnica Superior d'Enginyeria. Universitat \\ Rovira i Virgili. Campus Sescelades. 43007 Tarragona.
}

Spain

\section{Introduction}

Ionic liquids, also known as liquid electrolytes, ionic melts, ionic fluids, liquid salts, or ionic glasses, is a term generally used to refer to salts that form stable liquids. Nowadays it is considered that any organic salt that is liquid below $100^{\circ} \mathrm{C}$ falls into this category. They are usually formed by a large organic cation combined with an anion of smaller size and more symmetrical shape, although some symmetric cations are also combined with asymmetric anions to form ionic liquids. In spite of their strong charges, their asymmetry frustrates them from being solid below $100^{\circ} \mathrm{C}$ and this is why they remain liquid at these low temperatures.

These compounds are receiving great attention in recent years due to the fact that their properties can be tuned with a well-judged selection of the cation-anion pair, giving the opportunity to choose among a vast range of different ionic liquids. In addition, these compounds can also be tuned by the modification of the cation and/or the anion molecular structure adding appropriate functional groups in order to obtain ionic liquids with a set of desired physico-chemical properties, which are known as Task Specific Ionic Liquids (TSIL). At present time, hundreds of ionic liquids have been synthesized and there is virtually no limit in the number of possible counterion pairs and mixtures of them that can be obtained. Their tunable and unique properties make them a good alternative to conventional volatile organic compounds (VOCs) used in reaction and separation processes, solvents for cleaning and purification operations, as electrolytes in fuel cells, lubricants, heat transfer fluids and storage media (Brennecke and Maginn, 2001; Yokozeki and Shiflett, 2007; Tempel et al, 2008, Welton, 1999). For instance, understanding carbon dioxide solubility in ionic liquids has become an important issue for supercritical fluid extraction (Blanchard and Brennecke, 2001), gas separations in a supported ionic liquids membranes, alternative to the conventional amine scrubbing operation (Baltus et al., 2005) and in catalytic reactions (Wasserscheid and Keim, 2000). A summary of capabilities and limitations of ionic liquids in 
$\mathrm{CO}_{2}$ based separations respect to a variety of materials is provided in a recent and detailed contribution by Bara and co-authors (Bara et al., 2009).

These ionic liquids should be fully characterized before put into use for a specific application. Given the great amount of possible ionic liquids, and the need for accurate characterization, a good understanding about the dependence of their physico-chemical properties on their microscopic structure is desired in order to enhance the design of new ionic liquids for promising chemical and industrial processes in a systematic and efficient manner.

In spite of their prospective applications in several fields, there is an important gap between the synthesis and characterization of ionic liquids for potential different uses and the small amount of ionic liquids available in the market for industrial applications. This fact was already addressed in a recent report entitled "Accelerating ionic liquid commercialization" (BSC Incorporated Report 2004). Among the barriers identified to be circumvented for the commercialization of ionic liquids, one of them deals with fundamental understanding of compositional structure versus performance: ionic liquid commercialization requires discovery researchers to not only develop fundamental understanding of ionic liquid synthesis and properties, but to impart these liquids with the chemical processing features needed for important industrial applications and markets. Developing an understanding of the reactions that form ionic liquids, ionic liquid chemical and physical properties, mechanisms/functions in catalysis and separation systems, and interactions with other materials (e.g., container vessels) is essential to their usefulness in industrial applications. Since the combinations of ions for potential ionic liquids are virtually infinite, this is a needed but expensive and time-consuming task.

In this sense, modelling tools are excellent candidates to advance in this field, as they are cheap and fast. However, ionic liquids are extremely non-ideal systems, with charged and asymmetric ions and, hence, most classical equations will fail in capturing their physicochemical properties, unless the specific interactions are taken into account since the inception of the model. It is in this area where molecular modelling tools such as molecular simulations or molecular-based equations of state can play a key role, accelerating the characterization of these systems.

In recent years, some attempts trying to model the solubility of gases in ionic liquids in the framework of equations of state (EoS) and other modelling approaches have been done at different thermodynamic conditions and by different authors. A recent review summarizes most of them, together with their success and remaining challenges (Vega et al., 2010). In this review, the methods were classified according to the "molecular model" used to describe the ionic liquid in the different approaches: classical cubic equations, activity coefficient and group contribution methods, quantum methods and statistical mechanicsbased molecular approaches. One of the main advantages of using classical equations of state is that they are straightforward to use and they are present in any process simulator. However, several parameters, temperature and composition dependent, are needed, in most of the cases, to make them readily accessible for ionic liquids calculations. This is due to the fact that, in general, classical equations are missing an important part of the physical nature of ionic liquids. Even if the anion and cation are considered as a neutral pair, they exhibit polarity and hydrogen bonding ability, two facts not taken into account in an explicit manner in cubic EoSs. In addition, a major drawback in the use of cubic EoS is the fact that they require the critical parameters of the ionic liquids, which can only be obtained indirectly and with large uncertainties. This fact limits the predictive ability of these equations, and they are used for correlation purposes. 
A step forward in modelling is provided by the use of activity coefficient models and group contribution methods. One of the most valuable features of these methods is their applicability to multi-component systems under the assumption that local compositions can be described in this case by a relationship similar to that obtained for binary systems. However, one of the main disadvantages of these methods is that they depend on an extremely large amount of experimental data. Furthermore, the absence of the volume and surface parameters poses a hindrance in the calculation of the binary interaction parameters for UNIQUAC and UNIFAC models. These limitations can be overcome by the use of quantum-based models, such as COSMO-RS (see, for instead, the works of Shah et al., (2002) and of Guo et al. (2007)). In this method no experimental data is needed as an input to model the ionic liquids, being the main constraint the extensive computational time and also that, in some cases, the comparison with experimental data is only qualitative.

Some molecular-based equations of state such as lattice models, chain fluid theories and SAFT-type approaches have also been used to model ionic liquids and their behaviour in mixtures. The advantage of building a model for the molecule describing the physics of the system is related to a major predictive ability, hence enhancing the possibility of extending the range of application of the equation. In the next sections of this chapter, some examples of successful applications and current limitations of the use of one of these tools, the softSAFT equation, will be presented and discussed.

In addition to density-temperature and solubility data, transport properties such as viscosity, self diffusion and electric conductivity are particularly important parameters that must be accounted for in the selection of a given ionic liquid for its applications as alternative solvent or conductor. Ionic liquids present relatively high viscosities, normally of the same order of magnitude as oils. This poses a limitation to some of their possible applications. For instance, a low viscosity would be desirable in order to enhance mass transfer in two-phase separation processes with ionic liquids; the relatively long equilibration times in the absorption of gases by ionic liquids are a consequence of the low diffusivity of the solutes on a highly viscous medium (Anthony et al., 2002). The transport properties are also crucial when considering the reaction kinetics in a synthetic process or ion transport in an electrochemical device. Regarding the important role of ionic liquids as reaction media, the significance of transport properties is manifested, among other things, in the fact that chemical reactions can be diffusion limited even for highly soluble molecules (Wasserscheid \& Welton, 2003). In fact, most of the current research for the development of new and more useful ionic liquids is focused on the synthesis of products with improved transport properties (low viscosity, high electrical and heat conductivities, etc).

Great advance in the understanding of transport properties of ionic liquids, and the relationship between their structure and the properties, has been done thanks to molecular simulations. The work of several researchers, including Maginn and co-authors (Morrow \& Maginn, 2002; Maginn 2009 and references therein), Padua and Canongia-Lopes with coworkers (Lopes et al., 2004; Lopes \& Padua 2004; Padua et al., 2007) and Rey-Castro et al. (Rey-Castro \& Vega, 2006; Rey-Castro et al., 2007), among others, show good examples of these applications. In addition to these works, see also Bhargava et al. (2008) for an extensive bibliography on molecular simulation studies done in the field. These simulation results have greatly helped in understanding the local structure of ionic liquids, the solubility of some given compounds in them, and their transport properties. Although very useful from this perspective, the vast amount of computational time required to obtain these properties precludes the use of molecular simulations as standard tools to characterize these systems 
for screening purposes before selecting an optimum one for a given application. Hence, a combination of molecular simulations for transport properties together with equations of state or models for phase and solubility data remains an excellent alternative for a quick description of the selected ionic liquids.

As an illustration of the capabilities of modelling tools for understanding ionic liquids we present in the next sections some examples concerning their characterization within two different and complementary approaches: (1) the soft-SAFT equation of state (Blas \& Vega, 1997), used to predict the solubility of several compounds in different families of alkylimidazolium ionic liquids, as well as interfacial properties, and (2) classical molecular dynamic simulations, used to study transport properties like self-diffusion, viscosity and electrical conductivity of ionic liquids. These tools help in getting additional insights into the underlying mechanisms governing the behaviour of these systems, which is the basic knowledge needed for a rational design previous to their use.

\section{2. soft-SAFT as a tool to model the thermodynamic properties of ionic liquids}

\subsection{The soft-SAFT equation}

Several different theoretical approaches, correlations and equations of state (EoS) have been used to model ionic liquids and their behaviour in mixtures. We will highlight here the implementation of one of the most successful approaches for that purpose, the soft-SAFT equation of state. Soft-SAFT belongs to a family of SAFT-based equations in which the chain and association term in the equation come from Wertheim's first order thermodynamic perturbation theory (TPT1) for associating fluids (Wertheim, 1984a; 1984b; 1986a; 1986b).

SAFT provides a framework in which the effects of molecular structure on the thermodynamic properties can be separated and quantified. Hence, non-ideal contributions such as chain length and/or molecular shape, molecular association and polar interactions can be introduced in the development of the equation. An additional advantage of SAFT is that the underlying theory of the equation allows systematic extensions in a well-sounded manner. In this sense, different versions of the equation have been recently extended into several directions:

1. the calculation of second order thermodynamic derivative properties (Colina et al., 2002; Llovell \& Vega 2006b; 2007; Llovell et al., 2006; Laffite et al., 2006) and tricritical points (Vega \& Blas, 2000)

2. the precise characterization of the critical region of pure fluids and mixtures (Llovell et al., 2004; Llovell \& Vega 2006a; 2007) through a crossover treatment based on White's work (White, 2002; Salvino \& White, 1992) from the renormalization group theory or through other approaches (Kiselev \& Ely, 2000); and

3. the calculation of interfacial vapor-liquid and liquid-liquid properties by coupling the van der Waals density gradient theory to the soft-SAFT equation (Duque et al., 2004; Mejia et al., 2005; Mejia \& Vega, 2006; Vilaseca \& Vega, 2010) or a density functional theory to the SAFT-VR version (Blas et al., 2001; Gloor et al., 2004; Llovell et al., 2010a).

As other SAFT-type equations, soft-SAFT is written in terms of the total Helmholtz energy of the system. When applied to ionic liquids, the residual Helmholtz energy is written as:

$$
a^{\text {res }}=a^{\text {ref }}+a^{\text {chain }}+a^{a s s o c}+a^{\text {polar }}
$$

where $a^{\text {res }}$ is the residual Helmholtz free energy density of the system $\left(a^{\text {res }}=a^{\text {total }}-a^{\text {ideal }}\right)$. The superscripts ref, chain, assoc and polar refer to the contributions from the reference term, 
the formation of the chain, the association, and the polar interactions, respectively, depending on the system under study.

In soft-SAFT (Blas \& Vega, 1997; Blas \& Vega, 1998a; 1998b; Pàmies \& Vega, 2001) the reference term is a Lennard-Jones (LJ) spherical fluid (a "soft" reference fluid), which accounts for both, the repulsive and attractive interactions of the monomers forming the chain. For the case of mixtures, the same equation is used by applying the van der Waals one-fluid theory, with generalized Lorentz-Berthelot mixing rules:

$$
\sigma_{i j}=\eta_{i j}\left(\frac{\sigma_{i i}+\sigma_{j j}}{2}\right) \quad \text { and } \varepsilon_{i j}=\xi_{i j}\left(\varepsilon_{i i} \varepsilon_{j j}\right)^{1 / 2} \text {, }
$$

where $\eta_{i j}$ and $\xi_{i j}$ are the size and energy binary adjustable parameters, respectively. The equation is used in a purely predictive manner from the pure component parameters when $\eta_{i j}$ and $\xi_{i j}$ are equal to unity, while values different from unity mean the use of one or two binary parameters, taking into account the differences in size and/or energy of the segments forming the two compounds in the mixture. The parameter $\xi_{i j}$ is equivalent to $\left(1-\mathrm{k}_{\mathrm{ij}}\right)$ in most EoSs.

The chain and association terms come from Wertheim's theory (Wertheim 1984a; 1984b; 1986a; 1986b), and they are formally identical in the different versions of SAFT:

$$
\begin{gathered}
a^{\text {chain }}=\rho k_{B} T \sum_{i} x_{i}\left(1-m_{i}\right) \ln g_{L J} \\
a^{a s s o c}=\rho k_{B} T \sum_{i} x_{i} \sum_{\alpha}\left(\ln X_{i}^{\alpha}-\frac{X_{i}^{\alpha}}{2}\right)+\frac{M_{i}}{2}
\end{gathered}
$$

where $\rho$ is the molecular density, $T$ is the temperature, $m$ is the chain length, $x_{i}$ is the molar fraction of component $i, k_{B}$ is the Boltzmann constant and $g_{L J}$ is the radial distribution function of a fluid of LJ spheres at density $\rho_{m}=m \rho$, evaluated at the bond length $\sigma . M_{i}$ is the number of associating sites of component $i$, and $X_{i}^{\alpha}$ the mole fraction of molecules of component $i$ non bonded at site $\alpha$, which accounts for the contributions of all the associating sites in each species (see, for instance, Blas \& Vega 1997).

The leading multipolar term for fluids of linear symmetrical molecules, like carbon dioxide, nitrogen, acetylene, etc., is the quadrupole-quadrupole potential (Gubbins \& Twu, 1978). An expansion of the Helmholtz free energy density in terms of the perturbed quadrupolequadrupole potential with the Padé approximation was proposed by Stell et al. (1974):

$$
a^{q q}=a_{2} q q\left(\frac{1}{1-\frac{a_{3}{ }^{q q}}{a_{2}{ }^{q q}}}\right)
$$

Expressions for $a_{2} q q$ and $a_{3} q q$, the second and third-order perturbation terms, were derived for an arbitrary intermolecular reference potential (Twu et al., 1975). A detailed derivation of these expressions is given elsewhere (Gubbins \& Two, 1978). This term in the soft-SAFT EoS involves an additional molecular parameter, $Q$, the quadrupolar moment. 
In order to calculate interfacial properties, the soft-SAFT equation is extended by coupling it with the Density Gradient Theory (DGT) of van der Waals (van der Waals, 1894; translated by Rowlinson, 1976). Within the context of this theory, the Helmholtz energy density $a$ of the inhomogeneous fluid is expressed as a function of the mole density and its derivatives with respect to the space coordinates. It is also assumed that the density gradient is small compared to the reciprocal value of the intermolecular distance, thus allowing treating the density and its derivatives as independent variables. Then the function $a$ is expanded in a Taylor series about $a_{0}$, the Helmholtz free energy density of the homogeneous fluid at the local density $\rho$ and truncated after the second order term. This series may not converge but, because of the short range of the intermolecular potential, it is assumed to have at least an asymptotic validity (Bongiorno \& Davis, 1975). In the absence of an external potential, the expression for the Helmholtz energy of the system $A$ reads:

$$
A=\int\left[a_{0}(\rho)+\sum_{i} \sum_{j} \frac{1}{2} c_{i j} \nabla \rho_{i} \nabla \rho_{j}\right] d^{3} r
$$

where the integration is performed in the entire system volume and $\rho_{i}$ is the molar density of component $i$. The parameter $c_{i j}$ for the components $i$ and $j$ is known as the influence parameter (Bongiorno \& Davis, 1975). In this work we have assumed a constant value for $c$, obtained by fitting to experimental data, as previously done in other works (Kahl \& Enders 2000; 2002; Vilaseca \& Vega, 2010).

DGT also allows obtaining density profiles by the minimization of the total free energy of the system. Considering that the chemical potential of a species remains constant across the interface (Davis \& Scriven, 1982), the following Euler-Lagrange equations result from equation (5):

$$
\sum_{j} \nabla \cdot\left(c_{i j} \nabla \rho_{j}\right)-\frac{1}{2} \sum_{k} \sum_{j} \frac{\partial c_{k j}}{\partial \rho_{i}} \nabla \rho_{k} \cdot \nabla \rho_{j}=\frac{\partial\left(a_{0}\left(\rho_{0}\right)-\sum_{i} \rho_{i} \mu_{0 i}\right)}{\partial \rho_{i}} \quad i, j, k=1, \ldots, N
$$

where all symbols were previously defined. Equation (6) is mathematically a nonlinear boundary value problem. Details of the various numerical approaches to solve this equation are provided in the work by McCoy \& Davis (1979).

The interfacial tension is a macroscopical consequence of the density profile. Considering a planar interface and assuming that the density dependence of the influence parameter can be neglected, an expression that relates the interfacial tension to the square of the density gradient can be derived from equation (6) (Davis \& Scriven, 1982):

$$
\gamma=\sum_{i} \sum_{j} \int_{-\infty}^{\infty} c_{i j} \frac{d \rho_{i}}{d z} \frac{d \rho_{j}}{d z} d z=2 \int_{-\infty}^{\infty}\left[a_{0}(\rho)-\sum_{i} \rho_{i} \mu_{0 i}-p_{0}\right] d z
$$

where $\mu_{0}$ and $p_{0}$ are the equilibrium chemical potential and pressure, respectively, and $z$ is the direction perpendicular to the interface. The approximation $\partial c_{i j} / \partial \rho=0$ is supported by the works of McCoy and Davis (1979) and those of Carey et al. (1978a; 1978b; 1980). Further 
details on how to obtain the density profiles and interfacial tensions from these expressions can be obtained in the original references and in (Vilaseca \& Vega, 2010).

\subsection{The molecular models of the compounds}

In order to use the soft-SAFT EoS for a particular system a molecular model of each compound should be chosen. Based on results obtained from molecular dynamics simulations showing the ion pairing of these systems, Andreu and Vega (2007) modelled the $[\mathrm{Cn}-\mathrm{mim}]\left[\mathrm{BF}_{4}\right]$ and $[\mathrm{Cn}-\mathrm{mim}]\left[\mathrm{PF}_{6}\right]$ families as LJ chains with one associating site in each molecule (see Fig. 1). This model mimics the neutral pairs (anion plus cation) as a single chain molecule with this association site describing the specific interactions because of the charges and the asymmetry. The model has been used to accurately describe the solubility of $\mathrm{CO}_{2}$ in ionic liquids (Andreu \& Vega, 2007), as well as the absorption of $\mathrm{BF}_{3}$ in $\left[\mathrm{C}_{4}{ }^{-}\right.$ $\mathrm{mim}]\left[\mathrm{BF}_{4}\right]$ (Vega et al., 2010).
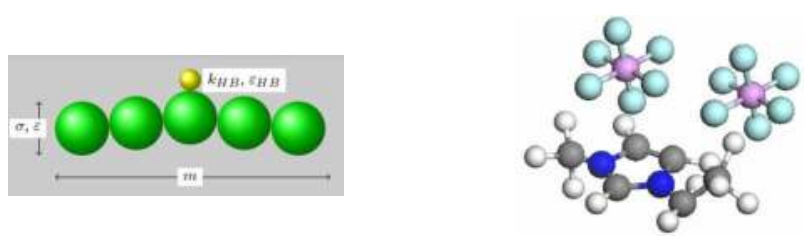

Fig. 1. Schematic representations of the $\left[\mathrm{C}_{\mathrm{n}}-\mathrm{mim}\right]\left[\mathrm{PF}_{6}\right]$ ionic liquid. Left: the soft-SAFT simplified model; right: all atom model.

As the delocalization of the anion electric charge due the oxygen groups enhances the possibility of interaction with the surrounding cations, the members of the alkylimidazolium- $\left[\mathrm{Tf}_{2} \mathrm{~N}\right]$ family are modelled as LJ chains with three associating sites in each molecule instead of one (let's say one " $\mathrm{A}$ " site, represented in yellow in Fig. 2, and 2 " $\mathrm{B}$ " sites, represented in red in Fig. 2). According to these interactions, we use a site " $A$ " representing the nitrogen atom interactions with the cation and a " $\mathrm{B}$ " site representing the delocalized charge due to the oxygen molecules on the anion (Andreu \& Vega, 2008). Each type of associating site is identically defined, but only $A B$ interactions between different ionic liquids molecules are allowed in the model, according to the modelled specific interactions on such systems.
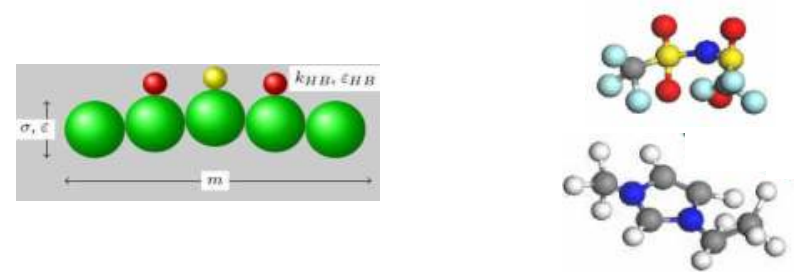

Fig. 2. Schematic representations of the $\left[\mathrm{C}_{\mathrm{n}}-\mathrm{mim}\right]\left[\mathrm{Tf}_{2} \mathrm{~N}\right]$ ionic liquid. Left: the soft-SAFT simplified model; right: all atom model.

To sum up, in all cases ionic liquids are modelled using five molecular parameters: $m$, the chain length, $\sigma$, the diameter of the spheres forming the chain, $\varepsilon$, the energy of interaction between them, $\kappa_{H B}$, the volume of association and $\varepsilon_{H B}$, the association energy. The chain 
length, size and energy parameters can be obtained by fitting to available densitytemperature data, while the association parameters were transferred from the alkanols (Pàmies, 2003), thus avoiding further fitting.

The carbon dioxide molecule is modelled (Dias et al., 2006; Belkadi et al., 2010) as a LJ chain in which explicit quadrupolar interactions are taken into account. In this case, the molecule is represented by $m, \sigma$, and $\varepsilon$, plus two additional parameters: the quadrupolar moment $Q$ and $x p$, defined as the fraction of segments in the chain that contain the quadrupole. This model has already been used with success to describe the behaviour of $\mathrm{CO}_{2}$ on different systems; see for instance the recent work of Belkadi et al. (2010) and references therein.

Alkanol molecules are represented as sites: each site is assigned parameter values to represent a group of atoms in the molecule of interest, such as $\mathrm{CH}_{3}, \mathrm{CH}_{2}$ or $\mathrm{CH}$ groups. In the soft-SAFT approach these molecules are modelled as $m$ LJ segments of equal diameter, $\sigma$, and the same dispersive energy, $\varepsilon$, bonded to form the chain. The hydroxyl group is mimicked by two square-well sites embedded off-centre in one of the LJ segments, with volume and energy of association $\kappa_{H B}$ and $\varepsilon_{H B}$, respectively. These two sites are represented by " $A$ " and "B" and only AB association is allowed (Pàmies 2003; Llovell \& Vega 2006a).

The water molecules are modelled as a single spherical LJ core with four embedded off-centre square well bonding sites. These four associating sites account for the two electron lone pairs and the two hydrogen sites of the water molecule. They are represented by two " $A$ " sites and two " $B$ " sites, and only $A B$ association is allowed between different molecules. This model has proven to give excellent results for pure water, including interfacial properties (Vilaseca and Vega, 2010) and also for water-hydrocarbon mixtures (Vega et al, 2009).

\subsection{Results for pure ionic liquids}

As an illustration we present here the application of this approach to characterize the $\left[\mathrm{C}_{n}{ }^{-}\right.$ $\operatorname{mim}]\left[\mathrm{Tf}_{2} \mathrm{~N}\right]$ family. The parameterization was done following the same assumptions as in previous works (Andreu \& Vega, 2007; 2008): the molecular parameters $m, \sigma$ and $\varepsilon$ were obtained by fitting to selected experimental density data from literature, while the association parameters were transferred from those of $\left[\mathrm{BF}_{4}\right]$ and $\left[\mathrm{PF}_{6}\right]$ imidazolium ionic liquids families. One of the greatest issues when modelling ionic liquids is the scattering in the experimental data found in the literature. Hence, after a detailed comparison with available data, we have used data from Tariq et al. (2010), which includes experimental data for a wide variety of members of the $\left[\mathrm{Tf}_{2} \mathrm{~N}\right]$ family in the whole liquid temperature range at atmospheric pressure. The choice was based on the extended temperature range investigated (from 293 till 473K) and also because of their agreement with other published data. Results for the temperature density diagram are shown in Fig. 3. Note that association parameters are kept constant for the whole family, with values $\varepsilon_{\mathrm{HB}} / \mathrm{k}_{\mathrm{B}}=3450 \mathrm{~K}$ and $\mathrm{K}_{\mathrm{HB}}=$ $2250 \AA^{3}$, respectively. See Llovell et al., (2010b), for more details on the procedure. As it can be observed, excellent agreement is achieved between the theory and the experimental data. $m, \sigma$ and $\varepsilon$ for the $\left[\mathrm{C}_{\mathrm{n}}-\mathrm{mim}\right]\left[\mathrm{Tf}_{2} \mathrm{~N}\right]$ family correlate with the molecular weight in the following way:

$$
\begin{gathered}
m=0.0056 M_{w}+3.8337 \\
m \sigma^{3}=1.9733 M_{w}+366.33\left(\AA^{3}\right) \\
m \varepsilon / k_{B}=3.3986 M_{w}+1043.3(\mathrm{~K})
\end{gathered}
$$


The correlations were done using the molecular parameters from $n=2$ till $n=8$, both included. The density $\mathrm{AAD} \%$ for this series of ionic liquids is $0.09 \%$. Using these correlations and keeping constant the volume and energy of association soft-SAFT can be used to predict the behaviour of heavier members of the series (see Fig. 3).

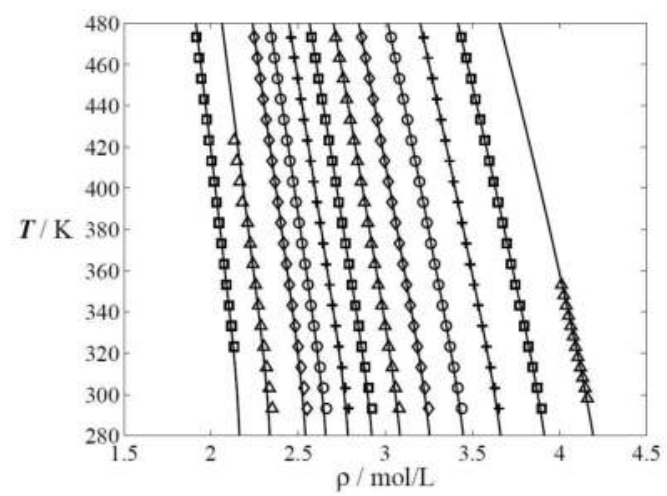

Fig. 3. Temperature-density diagram for the $\left[C_{n}-\operatorname{mim}\right]\left[T_{2} N\right]$ family, from $n=1$ (right) to $n=14$ (left), excepting $n=11$ and $n=13$. $\left[\mathrm{C}_{2}-\mathrm{mim}\right]\left[\mathrm{Tf}_{2} \mathrm{~N}\right]$ to $\left[\mathrm{C}_{8}-\mathrm{mim}\right]\left[\mathrm{Tf}_{2} \mathrm{~N}\right]$ compounds were used in the molecular parameters fitting procedure, while the rest of the family is predicted with the molecular parameters correlations (equations (8)-(10)).

The accuracy of the parameters for predicting other properties not included in the fitting procedure has been checked by comparing calculations from the equation with available experimental data on pressure-density. Fig. 4 depicts the diagram for $\left[\mathrm{C}_{2}-\mathrm{mim}\right]\left[\mathrm{Tf}_{2} \mathrm{~N}\right],\left[\mathrm{C}_{4^{-}}\right.$ $\operatorname{mim}][\mathrm{Tf} 2 \mathrm{~N}],\left[\mathrm{C}_{6}-\mathrm{mim}\right]\left[\mathrm{Tf}_{2} \mathrm{~N}\right]$ and $\left[\mathrm{C}_{8}-\mathrm{mim}\right]\left[\mathrm{Tf}_{2} \mathrm{~N}\right]$ as obtained with soft-SAFT with the parameters previously optimized up to a pressure of 60MPa. Several isotherms at 293 and 313K have been plotted and compared to experimental data (Gomes de Azevedo et al., 2005; Gardas et al., 2007). The agreement between the data and the prediction with soft-SAFT is very good, with no loss of accuracy with increasing pressures.

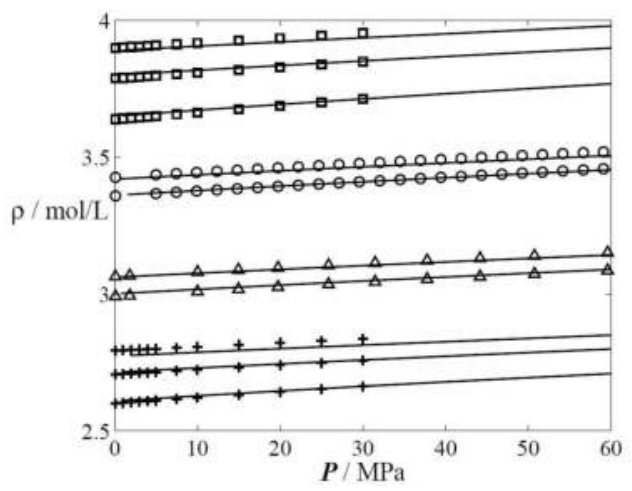

Fig. 4. Pressure-density diagram for $\left[\mathrm{C}_{2}-\mathrm{mim}\right]\left[\mathrm{Tf}_{2} \mathrm{~N}\right]$ (squares), $\left[\mathrm{C}_{4}-\mathrm{mim}\right]\left[\mathrm{Tf}_{2} \mathrm{~N}\right]$ (circles), $\left[\mathrm{C}_{6}\right.$ mim] $\left[\mathrm{Tf}_{2} \mathrm{~N}\right]$ (triangle up) and $\left[\mathrm{C}_{8}-\mathrm{mim}\right]\left[\mathrm{Tf}_{2} \mathrm{~N}\right]$ (crosses). Symbols: experimental data (Gomes de Azevedo et al., 2005; Gardas et al., 2007); solid lines: soft-SAFT calculations. 
The molecular parameters fitted to single-phase equilibrium data were used in a transferable manner to calculate interfacial properties. The only additional parameter within the soft-SAFT+DGT approach is the influence parameter. In this work we have optimized this parameter for each pure compound using interfacial tension experimental data from the triple to the critical point (Carvalho et al., 2008). The resulting values are given in Table 1.

\begin{tabular}{|c|c|}
\hline Compounds & $1{ }^{19} \mathrm{C}\left(\mathrm{J} \mathrm{m}^{5} \mathrm{~mol}^{-2}\right)$ \\
\hline$\left[\mathrm{C}_{2}-\mathrm{mim}\right]-\left[\mathrm{Tf}_{2} \mathrm{~N}\right]$ & 15.932 \\
\hline$\left[\mathrm{C}_{3}-\mathrm{mim}\right]-\left[\mathrm{Tf}_{2} \mathrm{~N}\right]$ & 16.540 \\
\hline$\left[\mathrm{C}_{4}-\mathrm{mim}\right]-\left[\mathrm{Tf}_{2} \mathrm{~N}\right]$ & 17.952 \\
\hline$\left[\mathrm{C}_{5}-\mathrm{mim}\right]-\left[\mathrm{Tf}_{2} \mathrm{~N}\right]$ & 20.100 \\
\hline$\left[\mathrm{C}_{6}-\mathrm{mim}\right]-\left[\mathrm{Tf}_{2} \mathrm{~N}\right]$ & 22.278 \\
\hline$\left[\mathrm{C}_{7}-\mathrm{mim}\right]-\left[\mathrm{Tf}_{2} \mathrm{~N}\right]$ & 24.857 \\
\hline$\left[\mathrm{C}_{8}-\mathrm{mim}\right]-\left[\mathrm{Tf}_{2} \mathrm{~N}\right]$ & 28.037 \\
\hline
\end{tabular}

Table 1. Optimized influence parameters of the $\left[\mathrm{C}_{\mathrm{n}}-\mathrm{mim}\right]\left[\mathrm{Tf}_{2} \mathrm{~N}\right]$ ionic liquid family.

Soft-SAFT+DGT results compared to experimental data (Carvalho et al., 2008) are presented in Fig. 5. As in the experimental case a decreasing interfacial tension value with the alkyl chain length is obtained. This behaviour is very surprising as it is contrary to the other chemical families where the interfacial tension increases as the chain length increases.

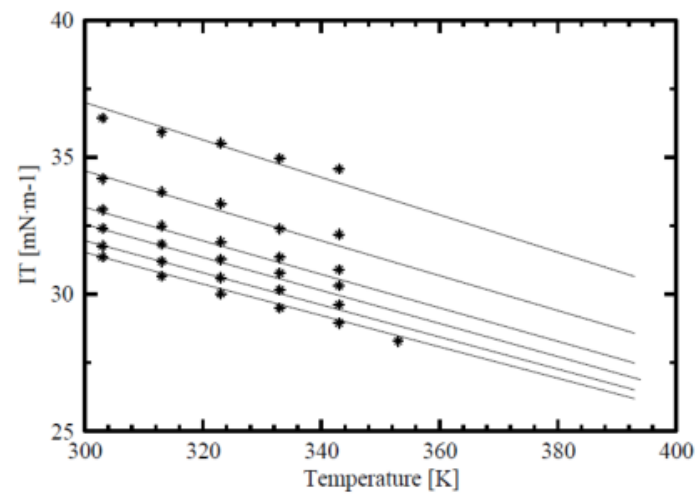

Fig. 5. Vapour-liquid interfacial tensions of the $\left[\mathrm{C}_{n}-\operatorname{mim}\right]\left[\mathrm{Tf}_{2} \mathrm{~N}\right]$ ionic liquid family, as a function of temperature, from top to bottom: $\left[\mathrm{C}_{2}-\mathrm{mim}\right]\left[\mathrm{Tf}_{2} \mathrm{~N}\right],\left[\mathrm{C}_{3}-\mathrm{mim}\right]\left[\mathrm{Tf}_{2} \mathrm{~N}\right],\left[\mathrm{C}_{4^{-}}\right.$ $\operatorname{mim}]\left[\mathrm{Tf}_{2} \mathrm{~N}\right],\left[\mathrm{C}_{5}-\mathrm{mim}\right]\left[\mathrm{Tf}_{2} \mathrm{~N}\right],\left[\mathrm{C}_{6}-\mathrm{mim}\right]\left[\mathrm{Tf}_{2} \mathrm{~N}\right]$ and $\left[\mathrm{C}_{7}-\mathrm{mim}\right]\left[\mathrm{Tf}_{2} \mathrm{~N}\right]$. Symbols: experimental data (Carvalho et al., 2008); lines: soft-SAFT+DGT calculations.

\subsection{Results for mixtures}

The solubility of $\mathrm{CO}_{2}$ in the ionic liquids $\left[\mathrm{C}_{2}-\mathrm{mim}\right]\left[\mathrm{Tf}_{2} \mathrm{~N}\right],\left[\mathrm{C}_{4}-\mathrm{mim}\right]\left[\mathrm{Tf}_{2} \mathrm{~N}\right]$ and $\left[\mathrm{C}_{6}{ }^{-}\right.$ $\operatorname{mim}]\left[\mathrm{Tf}_{2} \mathrm{~N}\right]$ over a wide temperature range $(313 \mathrm{~K}-453 \mathrm{~K})$ was calculated with soft-SAFT and results compared to available experimental data. These calculations were performed from pure component parameters (no mixture parameters adjusted), i.e., the soft-SAFT was used in a predictive manner. As depicted in Fig. 6 the agreement between the theoretical predictions and the experimental data is excellent in all cases, showing the robustness of the 
parameters obtained from pure fluid data and of the method of calculation. No specific interactions between $\mathrm{CO}_{2}$ and the ionic liquids were considered to obtain these results.
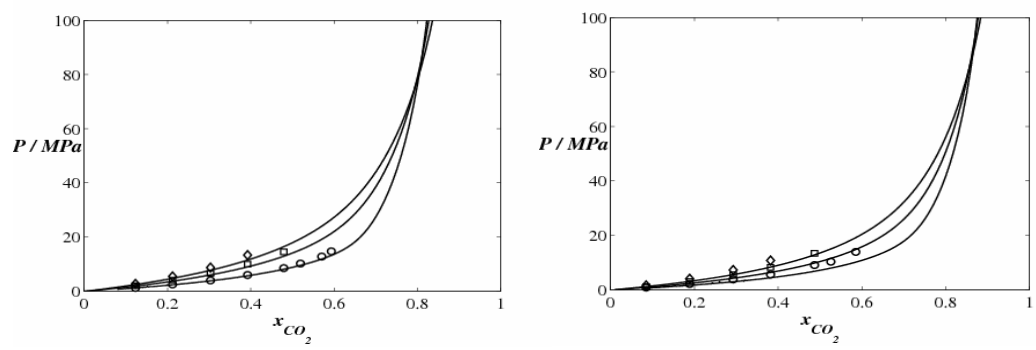

Fig. 6. Prediction of the solubility of $\left[\mathrm{C}_{2}-\mathrm{mim}\right]\left[\mathrm{Tf}_{2} \mathrm{~N}\right]$ (left) and $\left[\mathrm{C}_{4}-\mathrm{mim}\right]\left[\mathrm{Tf}_{2} \mathrm{~N}\right]$ (right) in $\mathrm{CO}_{2}$ at three different temperatures. Symbols experimental data (Raeissi \& Peters, 2009), lines: soft-SAFT calculations.

The solubility results of methanol and ethanol in $\left[\mathrm{C}_{4}-\mathrm{mim}\right]\left[\mathrm{Tf}_{2} \mathrm{~N}\right]$ were also modelled with soft-SAFT. These mixtures are challenging as alcohols are associating molecules with a hydroxyl group that will interact with the ionic liquid with interactions stronger than just van der Waals forces, being also localized in space. Results for these calculations are presented in Fig. 7. Good agreement is found between the soft-SAFT predictions and the measured experimental data (Verevkin, et al., 2005) in the whole range of compositions. It is important to remark that these are pure predictions from the equation. The agreement can be improved by using an adjustable binary parameter, hence losing the predictive power.

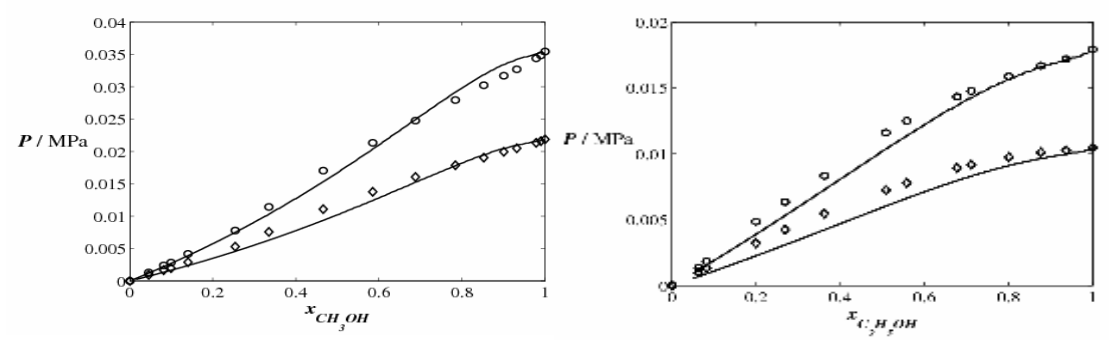

Fig. 7. Solubility of alkanols in $\left[\mathrm{C}_{4}-\mathrm{mim}\right]\left[\mathrm{Tf}_{2} \mathrm{~N}\right]$. Left: Pressure-composition diagram of a methanol $+\left[\mathrm{C}_{4}-\mathrm{mim}\right]\left[\mathrm{Tf}_{2} \mathrm{~N}\right]$ mixture at $303 \mathrm{~K}$ (diamonds) and 313K (squares). Right: Pressure-composition diagram of an ethanol $+\left[\mathrm{C}_{4}-\mathrm{mim}\right]\left[\mathrm{Tf}_{2} \mathrm{~N}\right]$ mixture at $303 \mathrm{~K}$ (diamonds) and 313K (squares). Symbols: experimental data (Verevkin, et al., 2005); lines: soft-SAFT predictions. Cross-associating values are calculated using the Lorentz-Berthelot rules.

The solubility of water in $\left[\mathrm{C}_{2}-\mathrm{mim}\right]\left[\mathrm{Tf}_{2} \mathrm{~N}\right]$ at several temperatures is shown in Fig.8. Vapourliquid equilibrium diagrams at $292.75 \mathrm{~K}, 303.15 \mathrm{~K}, 323.2 \mathrm{~K}$ and $353.15 \mathrm{~K}$ were predicted using the soft-SAFT equation and compared to experimental data (Husson et al., 2010). An excellent agreement it is found in the whole range of compositions. A liquid-liquid region has been detected over the constant pressure three-phase-line. Similar results can be seen in the pressure-composition diagram of a water $+\left[\mathrm{C}_{4}-\mathrm{mim}\right]\left[\mathrm{Tf}_{2} \mathrm{~N}\right]$ mixture at $353.15 \mathrm{~K}$, also shown in Fig. 8, again in very good agreement with the experimental measurements. 


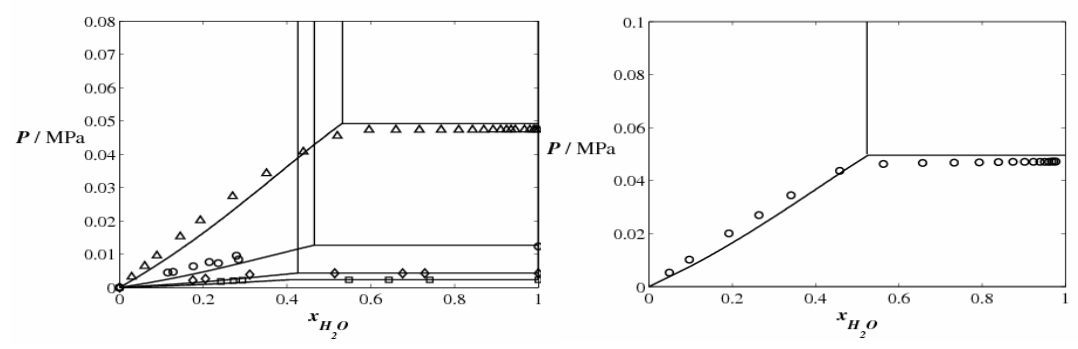

Fig. 8. Solubility of water in $\left[\mathrm{C}_{\mathrm{n}}-\mathrm{mim}\right]\left[\mathrm{Tf}_{2} \mathrm{~N}\right]$. Left: Pressure-composition diagram of a water $+\left[\mathrm{C}_{2}-\mathrm{mim}\right]\left[\mathrm{Tf}_{2} \mathrm{~N}\right]$ mixture at $292.75 \mathrm{~K}$ (squares), 303.15K (diamonds), 323.2K (circles) and 353.15K (triangles). Experimental data was taken from reference (Husson et al., 2010). Right: Pressure-composition diagram of a water $+\left[\mathrm{C}_{4}-\mathrm{mim}\right]\left[\mathrm{Tf}_{2} \mathrm{~N}\right]$ mixture at $353.15 \mathrm{~K}$. Symbols: experimental data (Nebig et al., 2007); lines: soft-SAFT predictions.

\section{Transport properties of ionic liquids by molecular simulations}

\subsection{Calculation of the transport coefficients through the Green-Kubo formalism}

As stated in the introduction, molecular simulations can be used as complementary tools to characterize ionic liquids from a modelling approach. The transport coefficients can be calculated through the corresponding Green-Kubo relations (Allen \& Tildesley, 1987; Frenkel \& Smit, 2002). Within this formalism, the self-diffusion coefficient (D) of each ion is calculated from its velocity autocorrelation function (vacf) through the following expression:

$$
D=\frac{1}{3 N} \int_{0}^{\infty} \sum_{i=1}^{N}\left\langle\overrightarrow{\mathbf{v}}_{i}\left(t_{0}+t\right) \cdot \overrightarrow{\mathbf{v}}_{i}\left(t_{0}\right)\right\rangle \mathrm{d} t
$$

Here the brackets $<\ldots>$ represent the average over all time origins $t_{0}$ within the trajectory, $\overrightarrow{\mathbf{v}_{i}}$ represents the velocity of the centre of mass of particle $i$ at any specific time, and $t$ is the delay time of the correlation function. The velocity autocorrelation function is a single particle function, and therefore the sum over all molecules in the system as well as the inclusion of the three velocity coordinates improves the statistics in the calculated coefficients (Rey-Castro \& Vega, 2006). In practical terms, the upper limit of the integral in equation (11) means that the integral must be calculated up to a point where the autocorrelation function decays to zero. In this work, an empirical exponential decay function has been fitted to the asymptotic part of the running integral in equation (11) in order to extrapolate the diffusion coefficients:

$$
D(t)=D+a \cdot \exp (-b \cdot t)
$$

where $D(t)$ is the running integral in equation (11), and $a, b$ are empirical fitting parameters. The shear viscosity $(\eta)$ at zero shear rate is calculated from the integral over time of the pressure tensor autocorrelation function following the Green-Kubo relation:

$$
\eta=\frac{V}{k_{\mathrm{B}} T} \int_{0}^{\infty}\left\langle P_{a \beta}\left(t_{0}+t\right) \cdot P_{a \beta}\left(t_{0}\right)\right\rangle \mathrm{d} t
$$


The brackets indicate that average must be taken over all time origins $t_{0}, V$ is the volume of the system, $T$ is the temperature and $k_{B}$ is the Boltzmann constant. $P_{a \beta}$ denotes the element $a \beta$ of the pressure tensor. Unlike self-diffusion, the shear viscosity is a collective function; hence, it cannot be statistically improved by averaging over the number of particles in the system. The elements of the pressure tensor are calculated during the simulation using the following expression:

$$
P_{\alpha \beta}=\frac{1}{V}\left[\sum_{j} m_{j} v_{\alpha j} v_{\beta j}+\frac{1}{2} \sum_{i \neq j} r_{\alpha i j} f_{\beta i j}\right]
$$

where, $m_{j}$ is the mass of particle $j, v_{j}$ is its velocity, while $r_{i j}$ and $f_{i j}$ represent the distance and the force between particles $i$ and $j$, respectively. The subscripts $a$ and $\beta$ refer to the corresponding components of the vectors.

The electrical conductivity, $\sigma$, is calculated as the time integral of the electrical current autocorrelation function:

$$
\sigma=\frac{1}{3 k_{\mathrm{B}} T V} \int_{0}^{\infty}\left\langle\overrightarrow{\mathbf{J}}\left(t_{0}+t\right) \cdot \overrightarrow{\mathbf{J}}\left(t_{0}\right)\right\rangle \mathrm{d} t
$$

where the electrical current $\mathbf{J}(t)$ is given by:

$$
\overrightarrow{\mathbf{J}}=\sum_{i=1}^{N} q_{i} \overrightarrow{\mathbf{v}}_{i}
$$

and $q_{i}$ represents the charge of ion $i$.

Like the shear viscosity, the electrical conductivity is a collective dynamical property, and for this reason suffers from relatively high statistical uncertainty. Again, an exponential decay function was fitted to the long-time behaviour of the integral of the autocorrelation function in order to obtain an extrapolated value of $\sigma$.

\subsection{The molecular models used in the MD simulations}

In order to investigate the influence of the molecular structure and temperature in the transport properties of ionic liquids, equilibrium molecular dynamics simulations were performed with two different models for the $\left[\mathrm{C}_{2}-\mathrm{mim}\right][\mathrm{Cl}]$ ionic liquid, the rigid model of Shim et al. (2005) and the flexible model proposed by Urahata and Ribeiro (2005).

In the rigid model of Shim et al., the united atom representation for the $\mathrm{CH}_{2}$ and $\mathrm{CH}_{3}$ groups is used. Hence, the cation is represented by a rigid body and its geometry (bond lengths, angles) was taken from experimental x-ray diffraction data obtained from crystals of $\left[\mathrm{C}_{2}-\right.$ mim][Br] (Elaiwi et al., 1995). The electrostatic description of the cation consists of fixed partial charges centred on the atoms (Hanke et al., 2001). The interaction potential in the system is represented by a sum of pairwise additive interatomic LJ and Coulombic potentials:

$$
U=\sum_{i=1}^{N-1} \sum_{j>1}^{N}\left\{U^{\mathrm{LJ}}\left(r_{i j}\right)+U^{\operatorname{Coul}}\left(r_{i j}\right)\right\}
$$


The model of Shim et al., sketched in Fig. 9, is based on the Amber force field for the Lennard-Jones (LJ) parameters of the individual atoms and makes use of the conventional Lorentz-Berthelot combining rules. The chloride atom is represented by a LJ sphere with $\sigma=4.4 \AA$ and $\varepsilon / \mathrm{k}_{\mathrm{B}}=50.4 \mathrm{~K}$ carrying a unit negative charge. It must be mentioned that there is a relatively large uncertainty in the parameterization of the force field of most of the common anions in ionic liquids, and of chloride ion in particular (Lopes et al., 2004). As far as the cation is concerned, the force field employed here is one of the simplest models found in bibliography (de Andrade et al., 2005), since it does not account for any intramolecular degree of freedom, nor the electronic polarizability of the molecule. Despite this, the model still incorporates basic molecular features of $\left[\mathrm{C}_{2}-\mathrm{mim}\right][\mathrm{Cl}]$, such as size, cation asymmetry and charge distribution.

The united atom representation for the $\mathrm{CH}_{2}$ and $\mathrm{CH}_{3}$ groups is also adopted in the flexible model (Urahata and Ribeiro, 2005), as well as for C-H moieties i.e. hydrogen atoms are not explicitly considered. The cation is therefore described by an 8 -site body. The model is sketched in Fig. 9. The interaction potential in the system is represented by two different contributions: the intermolecular and the intramolecular interactions. The intermolecular interactions are represented by two different pairwise additive contributions; a set of interatomic Lennard-Jones potentials between individual united atoms and a Coulombic potential term according to the different partial charges used in the model, also used in the rigid model. In addition to aforementioned intermolecular contributions, the different intramolecular interactions are also taken into account, including bond stretching ( $\mathrm{r}$ ), angle bending $(\theta)$ and torsion of dihedral angles $(\psi)$ :

$$
U_{\text {intra }}=\sum_{\text {bonds }} k_{b}\left(r-r_{\text {eq }}\right)^{2}+\sum_{\text {angles }} k_{\theta}\left(\theta-\theta_{\text {eq }}\right)^{2}+\sum_{\text {dihedrals }} k_{\psi}[1+\cos (n \psi-\delta)]
$$

Parameters of the intramolecular interactions were based on the all-atom model of Morrow and Maginn (2002). The LJ parameters were taken from the united model of Shah et al. (2002) and are based on the OPLS force field and makes use of the conventional LorentzBerthelot combining rules. The set of partial charges was proposed by Urahata and Ribeiro (2005). This model also assigns negative partial charges to nitrogen atoms, in line with the model of Hanke et al. (2001). The dispersive and electrostatic interactions between atoms belonging to the same dihedral angles were corrected by 0.5 in both cases. The chlorine anion is represented by a sphere carrying a unit negative charge, with LJ parameters from (Rey-Castro et al., 2007).
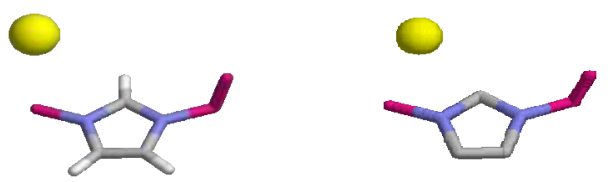

Fig. 9. Schematic representation of the 1-ethyl-3-methylimidazolium chloride ionic liquid, $\left[\mathrm{C}_{2}\right.$-mim $][\mathrm{Cl}]$, with the rigid model (Shim et al., 2005) (left) and the flexible model (Urahata and Ribeiro, 2005) (right). 


\subsection{Simulation details}

The simulated systems with the rigid and the flexible model consisted of cubic boxes with periodic boundary conditions and 125 ion pairs (1500 atoms). The starting configurations were simple cubic regular lattices.

For the rigid model the initial MD simulations were performed in the NPT ensemble (using the Melchionna modification of the Hoover algorithm (Melchionna et al., 1993), first at 1000K, then at $600 \mathrm{~K}$, and finally at the desired temperature, at least for 200 ps each stage, keeping an external pressure of 1 bar (Rey-Castro \& Vega, 2006). The systems were further equilibrated by velocity rescaling at constant volume and temperature for at least an additional $200 \mathrm{ps}$ interval. Finally, the production runs were obtained in the NVE ensemble. Shear viscosities were obtained from trajectories of $8 \mathrm{~ns}$, for which the components of the stress tensor were recorded in intervals of $20 \mathrm{fs}$. For the calculation of self-diffusion and conductivity shorter runs ( $800 \mathrm{ps})$ were employed, with position and velocity of all particles being recorded every $40 \mathrm{fs}$. The equations of motion were integrated through the Verlet and Fincham's implicit quaternion algorithms as implemented in the DL_POLY package (version 2.13) with a constant timestep of 0.002 ps. This timestep provided a good energy conservation with small fluctuations, the relative drift in the total energy being less than $2 \cdot 10^{-5}$ in $4 \mathrm{~ns}$. The Coulombic interactions were evaluated through the Ewald method using the convergence parameter $(\alpha)$ and largest reciprocal space vector $\left(k_{\max }\right)$ that yielded a relative accuracy of $1 \cdot 10^{-5}$ in the electrostatic energy. The accuracy of the Ewald sum was checked by comparison of the estimated Coulombic energy and the coulombic virial in absolute value.

Some simulation details were different in the case of the flexible model (Andreu \& Vega, 2010), given the different nature of the model. The initial configuration was equilibrated at 1000K for 500ps in the NpT ensemble, using the Nose-Hoover algorithm as implemented in DL_POLY 2.19 package, keeping an external pressure of 1 bar. A set of sequential simulations of 500ps were used in order to obtain the desired starting configurations by decreasing the temperature by $200 \mathrm{~K}$ at each stage. Previous to the production runs, a 200ps velocity rescaling simulations were performed for each temperature at constant volume. With this procedure, we set up the starting configurations at 6 different temperatures: 323 , $350,400,450,500$, and $550 \mathrm{~K}$.

The simulation scheme applied for the production runs in the flexible model simulations was the following: for each temperature, we performed a 4 ns run in the $\mathrm{NpT}$ ensemble. The thermostat and the barostat constants were set to $0.5 \mathrm{ps}$. The equilibrium properties for these simulations were calculated by averaging over the last 3ns. Then, two different sets of production runs in the NVE ensemble were done. The first set was $4 \mathrm{~ns}$ long and it was used to collect the statistical information for the calculation of the diffusion and conductivity coefficients. A second set of runs with a total of $15 \mathrm{~ns}$ was used to calculate the viscosity coefficients. The equations of motion were integrated through the Verlet Leapfrog algorithm as implemented in the DL_POLY 2.19 package. The timestep was set up to 0.002ps for all simulations, providing good energy conservation with small fluctuations, with a relative drift in the total energy being less than $3 \cdot 10^{-5}$. The Coulombic interactions were evaluated by the Single Particle Mesh Ewald (SPME) with an accuracy of $10^{-5}$ in the electrostatic energy. We selected the Ewald SPME method versus the standard Ewald sum due to its better performance when applied to the flexible model, as observed in several test simulations.

For both sets of simulations the real space cut-off for both the Lennard-Jones and the Coulombic interactions were set to $15 \AA$ and standard long range corrections to the potential energy and the virial of the system were applied. 
For the flexible model simulations two different approaches were used when calculating those properties: the first one was performing the simulations in the NVT ensemble, as has been done in several previous works, even they do not used the Green-Kubo relations the calculation but other statistical equivalent methods, and the second one was by simulating the system in the NVE ensemble, as previously done by some authors (Rey-Castro \& Vega, 2006; Rey-Castro et al., 2007).

\subsection{Flexibility and temperature effect on the transport properties of [ $\left.\mathrm{C}_{2}-\mathrm{mim}\right][\mathrm{Cl}]$}

In order to illustrate the use of MD simulations to calculate transport properties of ionic liquids we present results for self-diffusion, electrical conductivity and shear viscosity for the ionic liquid $\left[\mathrm{C}_{2}-\mathrm{mim}\right][\mathrm{Cl}]$ using a rigid model and a flexible model. This study provides additional insights into important aspects of the physical chemistry of ionic liquids, such as the relevance of cation-anion correlations, or the link between local structure and dynamic behaviour. The comparison with available experimental data provides a reference for the suggestion and validation of molecular force fields of ionic liquids. In addition, as one of the attractive features of the ionic liquids is the extended temperature range of liquid-state behaviour they offer, it is also important to understand the effect of temperature on the various transport properties.

The self-diffusion coefficients at temperatures $\mathrm{T}=380,404,450$ and $486 \mathrm{~K}$ were calculated from the Green-Kubo relations for the rigid model. The diffusion coefficients of the ions were calculated from the time integrals of the vacf, as explained in the previous subsection. As observed in Fig. 10 this coefficient is larger for the cation than for the anion at all the temperatures studied, in apparent contradiction with its larger size and mass compared with the $\mathrm{Cl}^{-}$ion. The fact that the lighter anions have smaller diffusion coefficients has also been observed experimentally, and it has been attributed to the smaller hindrance of the cation motion along the direction perpendicular to the nitrogen atoms on the ring plane.

The diffusion coefficients for the $\left[\mathrm{C}_{2}-\mathrm{mim}\right][\mathrm{Cl}]$ with the flexible model were obtained from NVT and NVE simulations, at different temperatures within the $323-500 \mathrm{~K}$ temperature range, just below its decomposition temperature (558K) (Huddleston et al., 2001). The diffusion coefficients were calculated following the same procedure as for the rigid model. The values obtained for the cation diffusion as well as for the anion, are almost one order of magnitude larger than the ones obtained with the rigid model, as shown in Fig. 10.

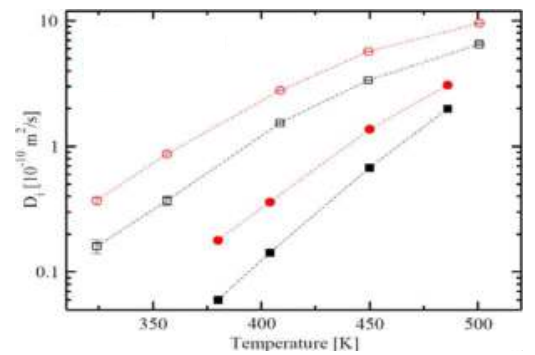

Fig. 10. Diffusion coefficient for the $\left[\mathrm{C}_{2}-\mathrm{mim}\right]^{+}$(circles) and $\mathrm{Cl}^{-}$(squares) ions calculated by the Green-Kubo relations using the rigid model (full symbols) and the flexible model from the NVE ensemble (open symbols). Results obtained for the flexible model in the NVT ensemble were very similar to the NVE ensemble and are not presented here. The symbols represent MD simulation results while the lines are just guides to the eyes. 
Fig. 11 depicts a comparison between simulated and experimental values of the shear viscosity at different temperatures. It is clearly observed that MD simulations performed with the rigid model overestimate this property by ca. one order of magnitude while the flexible model reproduces quite well the experimental data, indicating that flexibility is a key property in a molecular model regarding the viscosity of these ionic liquids.

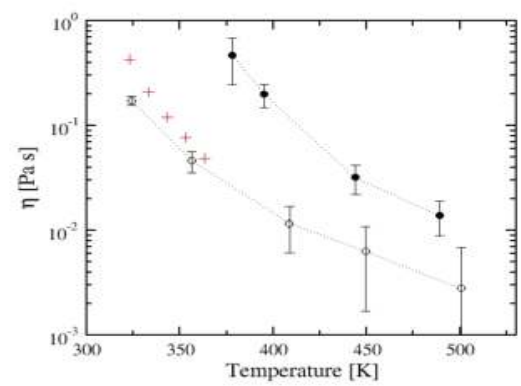

Fig. 11. Shear viscosity for the $\left[\mathrm{C}_{2}-\mathrm{mim}\right][\mathrm{Cl}]$ ionic liquid at different temperatures. Solid symbols are results obtained by the rigid model, while open symbols are the values from the flexible model, using the Green-Kubo formalism in the NVE simulations. Crosses represent experimental (Earle \& Seddon, 2002). The lines are just a guide to the eyes.

The ionic conductivity was also evaluated by the GK approach. However, as the mechanism of charge transport in these systems is related with the process of self-diffusion of the ions it is also possible to relate electric conductivity with the diffusion coefficients of the cation and the anion, known as the Nernst-Einstein relation (NE) (Hansen \& McDonald, 1986):

$$
\sigma=\frac{e^{2}}{k_{\mathrm{B}} T} \sum_{i} \rho_{i} q_{i} D_{i}
$$

where $e$ is the electric charge unit, $\rho$ and $q$ are the molar density and charge of the ions, respectively, and $i$ denotes cation or anion. Deviations from equation (19) are interpreted in terms of cross-correlations among ions. Thus, if the ratio between the experimental value of $\sigma$ and the conductivity calculated from NE is smaller than unity, then a significant fraction of oppositely charged ions are moving together in the time scale of diffusive motion. The motion of these neutral, short-lived ion clusters contributes therefore to self-diffusion, but not to the net charge transport. The values of the conductivity estimated using the GK relations and the NE relations with the diffusion coefficients obtained from the MD simulations are depicted in Fig. 12. Results obtained with the rigid model show that the molecular model does not lead to a significant overall cross-correlation among ions and, therefore, cation and anion behave as independent ions regarding diffusion and charge transport; however, this is not the case for the flexible model. Results from the NE relation show higher values with deviation becoming more important as the temperature increases, indicating some kind of correlation between ions.

In general, in electrolyte solutions, the conductivity is often found to be inversely proportional to viscosity (Xu et al., 2003), a behaviour that is usually called Walden's rule: 


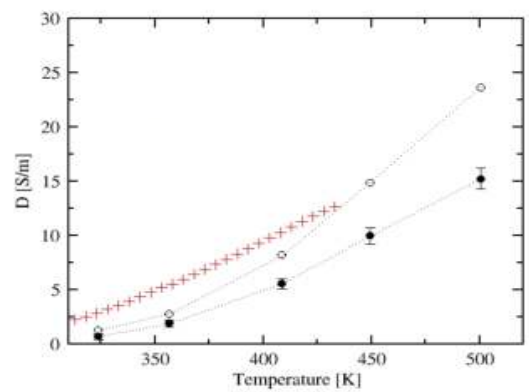

Fig. 12. The ionic conductivity evaluated by the Green-Kubo approach (solid symbols) and by the Nernst-Einstein relation (open symbols). The model used in both cases was the flexible model. Experimental data (crosses) was taken from (Vila et al., 2007).

$$
\Lambda \eta=\text { constant }
$$

where $\Lambda$ is the molar conductivity:

$$
\Lambda=\frac{\sigma M}{\rho}
$$

and $\sigma, \mathrm{M}, \rho$ are the electrical conductivity $\left(\mathrm{S} \cdot \mathrm{m}^{-1}\right)$, molecular weight and density, respectively. Ideally, the Walden product is independent of the temperature for a given ionic liquid. It has been found that most ionic liquids fit this linear relationship. Furthermore, the values of the Walden product have been found to be fairly independent of the presence of traces of water (Widegren et al., 2005). However, relatively small to significant variations in the Walden products with temperature have been described in ionic liquids based on alkyl/arenyltrifluoroborate anions (Zhou et al., 2005). The experimental fulfillment of equation (21) indicates that the density of mobile charge carriers in an ionic liquid is strongly correlated with its viscosity.

The application of Walden's rule in the MD simulation results is represented in Fig. 13. A good linear relationship $\log \Lambda$ vs. $\log \eta^{-1}$ is obtained, with a slope of 0.9 , close to the

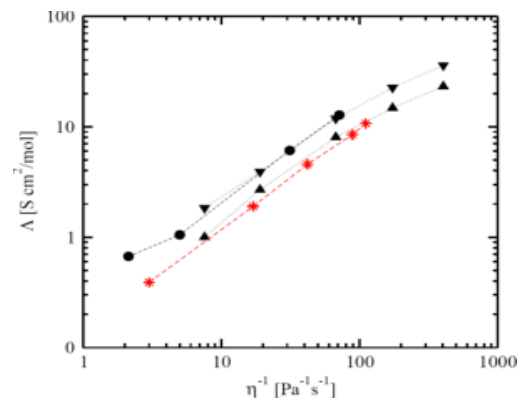

Fig. 13. Walden plot of the molar conductivity and shear viscosity calculated from MD simulations of $\left[\mathrm{C}_{2}\right.$-mim] $[\mathrm{Cl}]$ at different temperatures. Circles: the rigid model (Rey-Castro \& Vega, 2006), triangles up: the flexible model using the GK relations and triangles down: the flexible model and the NE relations (Andreu \& Vega, 2010). The red asterisks were calculated from the experimental conductivities (Fannin et al., 1984) and viscosities (Seddon et al. 2002), respectively. 
theoretical value of 1 , and in excellent agreement with experimental results. Deviations are observed for very low viscosities. The behaviour of the flexible model with properties obtained from the NE relations overlaps with those obtained with the rigid model, while results from the flexible model with transport properties calculated from GK equations are lower and in almost quantitative agreement with the experimental data.

\section{Conclusions and future directions}

We have presented here an overview and some selected results on the application of two refined and complementary tools for obtaining thermodynamic and transport properties of ionic liquids from a molecular perspective: a molecular-based equation of state (named softSAFT) for obtaining PVT data, as well as solubility of gases and mixtures behaviour, and a molecular dynamic procedure to calculate transport properties. In both cases the methods were used in a predictive manner and compared to experimental data in order to assess the validity of the model and to empower them with predictive capabilities for other properties. Concerning the application of soft-SAFT to these systems, it has been shown that a simple model and the appropriate selection of experimental data to obtain the pure component parameters give excellent predictive results for different mixtures. In particular, the procedure was applied to the $\left[\mathrm{C}_{\mathrm{n}}-\mathrm{mim}\right]\left[\mathrm{Tf}_{2} \mathrm{~N}\right]$ family and mixtures of these with other compounds. The molecular parameters obtained from density-temperature data of the pure fluids were tested for pressure-density and interfacial property data, providing quantitative agreement with experimental results. Pure component parameters were also used to predict the solubility of $\mathrm{CO}_{2}$ in selected ionic liquids from this family, as well as alkanol $+\left[\mathrm{C}_{\mathrm{n}}-\right.$ $\operatorname{mim}]\left[\mathrm{Tf}_{2} \mathrm{~N}\right]$ and water $+\left[\mathrm{C}_{\mathrm{n}}-\mathrm{mim}\right]\left[\mathrm{Tf}_{2} \mathrm{~N}\right]$ mixtures, obtaining excellent agreement with experimental data in all cases. Although the results obtained from soft-SAFT are also very encouraging, given the relative simplicity of the model, its predictive power and the agreement obtained with experimental data, the main limitation of the approach is that it considers the anion and cation as a unique molecule. Considering the cation and anion as two independent species will empower the equation with more predictive power.

Regarding transport properties, the aim of this study was to analyze the ability of a simple molecular model of an ionic liquid to describe the behavior of some transport properties as a function of the temperature as well as their mutual relationships, through MD simulations. In addition, the effect of the flexibility on the transport properties was also examined by using two models of the same ionic liquid, a rigid and a flexible one.

The diffusion coefficients, the ionic conductivity and the zero-shear viscosity coefficients of $\left[\mathrm{C}_{2}\right.$-mim $][\mathrm{Cl}]$ were computed in a wide range of temperatures by using the Green-Kubo formalism and results compared to experimental data. We showed that this approach is suitable when analyzing the properties of this light ionic liquid. The inclusion of the internal degrees of freedom on the cation description is an essential ingredient when the short time scale behaviour of the anion/cation dynamics was analyzed. The model was able to reproduce the experimental measurement of those transport properties in a wide range of temperatures, in closer agreement to experimental data than the rigid model. The simulations reproduce remarkably well the slope of the Walden plots obtained from experimental data of $\left[\mathrm{C}_{2}-\mathrm{mim}\right][\mathrm{Cl}]$, confirming that temperature does not alter appreciably the extent of ion pairing. However, further studies on the dynamics of relaxation of the solvation shells are suggested in order to corroborate these conclusions. All our results reinforce the importance of including internal degrees of freedom, such as flexibility, for 
calculating transport properties. It would also be interesting to explore whether other more refined force fields than the non-polarizable, united atom model used in this work will lead to a different description of the collective dynamics of cations and anions in the melt.

\section{Acknowledgements}

We are very grateful to Carlos Rey-Castro for his contribution to this work. Discussions with Joao A.P. Coutinho and John Prausnitz are also acknowledged. F. Llovell acknowledges a JAE-Doctor fellowship from the Spanish Government. This work has been partially financed by the Spanish government, Ministerio de Ciencia e Innovación, under projects CTQ200805370/PPQ, NANOSELECT and CENIT SOST-CO2 CEN2008-01027. Additional support from Carburos Metálicos, Air Products group, and from the Catalan government, under projects SGR2005-00288 and 2009SGR-666, is also acknowledged.

\section{References}

Allen, M. P. \& Tildesley, D. J. (1987). Computer Simulation of Liquids; Oxford University Press: New York.

Andreu, J.S. \& Vega, L. F. (2007). Capturing the Solubility Behavior of $\mathrm{CO}_{2}$ in Ionic Liquids by a Simple Model. J. Phys. Chem. C 111, 16028-16034.

Andreu, J.S. \& Vega, L. F. (2008). Modeling the Solubility Behavior of $\mathrm{CO}_{2}, \mathrm{H}_{2}$, and Xe in [Cn-mim][Tf 2 N] Ionic Liquids. J. Phys. Chem. B 112, 15398-15406.

Andreu, J.S. \& Vega, L.F. (2010). On the Transport properties of [emim]Cl through the Green Kubo formalism. Submitted.

Anthony, J. L.; Maginn, E. J. \& Brennecke, J. F. (2002). Solubilities and Thermodynamic Properties of Gases in the Ionic Liquid 1-n-Butyl-3-methylimidazolium Hexafluorophosphate. J. Phys. Chem. B, 106, 7315-7320.

Baltus, R.E.; Counce, R.M.; Culbertson, B.H. ; Luo, H.; DePaoli, D. W.; Dai, S. \& Duckworth, D.C. (2005). Examination of the potential of ionic liquids for gas separations. Sep. Sci. Technol. 40, 525.

Bara, J. E. ; Carlisle, T. K. ; Gabriel, C. J.; Camper, D.; Finotello, A.; Gin, D. L. \& Noble, R. (2009).Effects of temperature and anion species on CO2 permeability and CO2/N2 separation coefficient through ionic liquid membranes. Ind. Eng. Chem. Res. 48, 2739-2751.

Belkadi, A.; HadjKali, M.K.; Llovell, F.; Gerbaud, V. \& Vega, L.F. (2010). Soft-SAFT modeling of vapor-liquid equilibria of nitriles and their mixtures. Fluid Phase Equilib. 289, 191-200.

Bhargava B.L.; Balasubramanian, S. \& Klein M.L. (2008). Modelling room temperature ionic liquids. Chem Commun (Camb), 29, 3339-3351.

Blanchard, L.A. \& Brennecke, J.F. (2001). Recovery of Organic Products from Ionic Liquids Using Supercritical Carbon Dioxide. Ind. Eng. Chem. Res. 40, 287-292.

Blas, F.J.; del Rio, E.M.; de Miguel, E. \& Jackson, G. (2001). An examination of the vapourliquid interface of associating fluids using a SAFT-DFT approach. Mol. Phys. 99, 1851-1865.

Blas, F.J. \& Vega, L.F. (1997). Thermodynamic behaviour of homonuclear and heteronuclear Lennard-Jones chains with association sites from simulation and theory. Mol. Phys., 92, 135-150. 
Blas, F. J.; Vega, L. F. (1998a). Critical behavior and partialmiscibility phenomena in binary mixtures of hydrocarbons by the statistical associating fluid theory. J. Chem. Phys. 109, 7405-7413.

Blas, F. J.; Vega, L. F. (1998b). Prediction of Binary and Ternary Diagrams Using the Statistical Associating Fluid Theory (SAFT) Equation of State. Ind. Eng. Chem. Res. 1998,37, 660-674.

Bongiorno, V. \& Davis, H.T. (1975). Modified van der Waals theory of fluids interfaces. Physical Review A 12, 2213-2224.

Brennecke, J.F. \& Maginn, E.J. (2001). Ionic Liquids: Innovative Fluids for Chemical Processing. AIChE J. 47, 2384-2389.

BCS Incorporated Report “Accelerating Ionic Liquid Commercialization. Research Needs to Advance New Technology“ June 2004, report supported by the Chemical Industry VISION2020 Technology Partnership, the Department of Energy of USA and the American Chemical Society.

Cadena, C.; Zhao, Q.; Snurr, R. Q. \& Maginn, E. J. (2006). Molecular modeling and experimental studies of the thermodynamic and transport properties of pyridinium-based ionic liquids. J. Phys. Chem. B 110, 2821-2832.

Canongia Lopes, J. N. \& Padua, A. A. H. (2006). Nanostructural Organization in Ionic Liquids. J. Phys. Chem. B 110, 3330-3335.

Carey, B.S. ; Scriven, L.E. \& Davis, H.T. (1978a). Semiempirical theory of surface tensions of pure normal alkanes and alcohols. AIChE J. 24, 1076-1080.

Carey, B.S. ; Scriven, L.E. \& Davis, H.T. (1978b). On gradient theories of fluid interfacial stress and structure. Journal of Chemical Physics 69, 5040-5049.

Carey, B.S. ; Scriven, L.E. \& Davis, H.T. (1980). Semiempirical theory of surface tensions of binary systems. AIChE J. 26, 705-711.

Carvalho, P. J. ; Freire, M. G., Marrucho, I. M.; Queimada, A. J. \& Coutinho, J. A. P. (2008). Surface Tensions for the 1-Alkyl-3-methylimidazolium Bis(trifluoromethylsulfonyl)imide Ionic Liquids J. Chem. Eng. Data 53, 1346-1350.

Colina, C.M.; Turrens, L.F.; Olivera-Fuentes, C.; Gubbins, K.E. \& Vega, L.F. (2002). Predictions of the Joule-Thomson Inversion Curve for the n-Alkane Series and Carbon Dioxide from the Soft-SAFT Equation of State. Ind. Eng. Chem. Res. 41, 10691075 .

de Andrade, J.; Boes, E. S. \& Stassen, H. (2005). In Ionic Liquids IIIA: Fundamentals, Progress, Challenges, and Opportunities, Properties and Structure; Rogers, R. D., Seddon, K. R., Eds.; American Chemical Society: Washington DC, Vol. 901; pp 118.

Davis, H.T. \& Scriven, L. E. (1982). Stress and structure in fluid phase interfaces. Advances in Chemical Physics 49, 357-454.

Dias, A.M.A.; Carrier, H.; Daridon, J.L.; Pàmies, J.C.; Vega, L.F.; Coutinho, J.A.P. \& Marrucho, I.M. (2006). Vapor-Liquid Equilibrium of Carbon DioxidePerfluoroalkane Mixtures: Experimental Data and SAFT Modeling. Ind. Eng. Chem. Res. 45, 2341-2350.

Duque, D.; Pàmies, J.C. \& Vega, L.F. (2004). Interfacial properties of Lennard-Jones chains by direct simulation and density gradient theory. J. Chem. Phys. 121, 11395-11401.

Earle M. J. \& Seddon K. R. (2002). In Clean Solvents; American Chemical Society: Washington, DC, p 10-25. 
Elaiwi, A.; Hitchcock, P. B.; Seddon, K. R.; Srinivasan, N.; Tan, Y. M.; Welton, T. \& Zora, J. A. (1995). Hydrogen bonding in imidazolium salts and its implications for ambienttemperature halogenoaluminate(III) ionic liquids. J. Chem. Soc., Dalton Trans. 34673472 .

Fannin, A. A.; Floreani, D. A.; King, L. A.; Landers, J. S.; Piersma, B. J.; Stech, D. J.; Vaughn, R. L.; Wilkes, J. S. \& Williams, J. L. (1984). Properties of 1,3-dialkylimidazolium chloride-aluminum chloride ionic liquids. 2. Phase transitions, densities, electrical conductivities, and viscosities. J. Phys. Chem. 88, 2614-2621.

Frenkel, D. \& Smit, B. (2002). Understanding Molecular Simulation. From algorithms to applications, 2nd ed.; Academic Press.

Gardas, R. L.; Freire, M. G.; Carvalho, P. J.; Marrucho, I. M.; Fonseca, I. M. A.; Ferreira A. G. M. \& Coutinho, J. A. P. (2007). PGT Measurements of Imidazolium-Based Ionic Liquids. J. Chem. Eng. Data 52, 1881-1888.

Gloor, G.J.; Jackson, G.; Blas, F.J.; del Rio, E.M. \& de Miguel, E. (2004). An accurate density functional theory for the vapor-liquid interface of associating chain molecules based on the statistical associating fluid theory for potentials of variable range. $J$. Chem. Phys. 121, 12740-12759.

Gomes de Azevedo R., Esperança J.M.S.S., Szydlowskia J., Visak Z.P., Pires P.F., Guedes H.J.R., Rebelo L.P.N., Thermophysical and thermodynamic properties of ionic liquids over an extended pressure range: [bmim][NTf2] and [hmim][NTf2]. J. Chem. Thermod. (2005), 37, 888-899.

Gubbins, K. E.; Twu, C. H. (1978). Thermodynamics of polyatomic fluid mixtures. I. Theory. Chem. Eng. Sci. 33, 863-868

Guo, Z.; Lue, B.-M.; Thomsen, K.; Meyer, A.S. \& Xu, X. (2007). Predictions of flavonoid solubility in ionic liquids by COSMO-RS: experimental verification, structural elucidation, and salvation characterization. Green Chem. 9, 1362-1373.

Hanke, C. G.; Price, S. L. \& Lynden-Bell, R. M. (2001). Intermolecular potentials for simulations of liquid imidazolium salts. Mol. Phys. 99, 801-809.

Hansen, J. P. \& McDonald, I. R. (1986). Theory of Simple Liquids; Academic Press.

Huddleston, J. G.; Visser, A. E.; Reichert, W. M.; Willauer, H. D.; Broker, G. A. \& Rogers, R. D. (2001). Characterization and comparison of hydrophilic and hydrophobic room temperature IL incorporating the imidazolium cation. Green Chem. 3, 156-164.

Husson, P; Pison, L; Jacquemin, J \& Gomes, M.F.C. (2010). Influence of water on the carbon dioxide absorption by 1-ethyl-3-methylimidazolium bis(trifluoromethylsulfonyl)amide. Fluid Phase Equilib. 294, 98-104.

Kahl, H. \& Enders, S. (2000). Calculation of surface properties of pure fluids using density gradient theory and SAFT-EOS. Fluid Phase Equilib. 172, 27-42.

Kahl, H. \& Enders, S. (2002), Interfacial properties of binary mixtures. Physical Chemistry Chemical Physics 4, 931-936.

Kiselev, S.B. \& Ely, J.F. (2000). Simplified crossover SAFT equation of state for pure fluids and fluid mixtures. Fluid Phase Equilib. 174, 93-113.

Krummen, M.; Wassersccheid, P.; Gmehling, J. (2002). Measurement of Activity Coefficients at Infinite Dilution in Ionic Liquids Using the Dilutor Technique. J. Chem. Eng. Data 47, 1411-1417. 
Lafitte, T.; Bessières, D.; Piñeiro, M. M. \& Daridon, J.L. (2006). Simultaneous estimation of phase behavior and second-derivative properties using the statistical associating fluid theory with variable range approach. J. Chem. Phys. 124, 024509: 1-16.

Llovell, F.; Pàmies, J.C. \& Vega, L.F. (2004). Thermodynamic properties of Lennard-Jones chain molecules: Renormalization-group corrections to a modified statistical associating fluid theory. J. Chem. Phys. 121, 10715-10724.

Llovell, F. \& Vega, L.F. (2006a). Global Fluid Phase Equilibria and Critical Phenomena of Selected Mixtures Using the Crossover Soft-SAFT Equation. J. Phys. Chem. B 110, 1350-1362.

Llovell, F. \& Vega, L.F. (2006b). Prediction of Thermodynamic Derivative Properties of Pure Fluids through the Soft-SAFT Equation of State. J. Phys. Chem. B. 110, 11427-11437.

Llovell, F.; Peters, C.J. \& Vega, L.F. (2006). Second-order thermodynamic derivative properties of selected mixtures by the soft-SAFT equation of state. Fluid Phase Equilib. 248, 115-122.

Llovell, F. \& Vega, L.F. (2007). Phase equilibria, critical behavior and derivative properties of selected n-alkane/n-alkane and n-alkane/1-alkanol mixtures by the crossover softSAFT equation of state. J. Supercrit. Fluids 41, 204-216.

Llovell, F.; Galindo, A.; Blas, F.J.; Jackson, G. (2010a). Classical density functional theory for the prediction of the surface tension and interfacial properties of fluids mixtures of chain molecules based on the statistical associating fluid theory for potentials of variable range. J. Chem. Phys. 133, 024704: 1-19.

Llovell, F.; Valente, E.; Vilaseca, O. \& Vega, L.F. (2010b). Modelling complex associating mixtures with [Cn-mim] $\left[\mathrm{Tf}_{2} \mathrm{~N}\right]$ Ionic Liquids with the soft-SAFT equation. Submitted.

Lopes, J.N.C.; Deschamps, J. \& Padua, A.A.H. (2004). Modeling ionic liquids using a systematic all-atom force field. J. Phys. Chem. B 108, 2038-2047.

Lopes, J. N.C. \& Padua, A.A. H. (2004). Molecular force field for ionic liquids composed of triflate or bistriflylimide anions. J. Phys. Chem. B 108, 16893-16898.

Lopes, J.N.C. ; Shimizu, K.; Padua, A.A.H. ; Umebayashi, Y. ; Fukuda, S.; Fujii, K. \& Ishiguro, S.I. (2008). A tale of two ions: The conformational landscapes of bis(trifluoromethanesulfonyl)amide and N,N-dialkylpyrrolidinium. J. Phys. Chem. B $112,1465-1472$.

Lopes, J.N.C.; Padua, A.A.H. \& Shimizu, K. (2008). Molecular force field for ionic liquids IV: Trialkylimidazolium and alkoxycarbonyl-imidazolium cations; alkylsulfonate and alkylsulfate anions. J. Phys. Chem. B 112, 5039-5046.

Maginn, E.J. (2009). Atomistic simulation of ionic liquids Reviews in Computational Chemistry vol 26 Ed. K B Lipkowitz, R Larter and T Cundari 2009 (Hoboken, NJ: Wiley).

Maginn, E.J. (2009). E. J. Maginn, Molecular simulation of ionic liquids: current status and future opportunities. J. Phys. Cond. Matter 21, 373101:1-17.

McCoy, B.F. \& Davis, H.T. (1979). Free-energy theory of inhomogeneous fluids. Physical Review A 20, 1201-1207.

Mejia, A.; Pàmies, J.C.; Duque, D.; Segura, H. \& Vega, L.F. (2005). Phase and interface behaviors in type-I and type-V Lennard-Jones mixtures: Theory and simulations. $J$. Chem. Phys. 123, 034505: 1-10.

Mejía, A. \& Vega, L.F. (2006). Perfect wetting along a three-phase line: Theory and molecular dynamics simulations. J. Chem. Phys. 124, 244505: 1-7. 
Melchionna, S.; Ciccotti, G. \& Holian, B. L. (1993). Hoover NPT dynamics for systems varying in shape and size. Mol. Phys. 78, 533-535.

Morrow, T. \& Maginn, E. J. (2002). Molecular dynamics study of the ionic liquid 1-n-butyl-3methylimidazolium hexafluorophosphate. J. Phys. Chem. B 106, 12807-12813.

Nebig, S.; Bolts, R. \& Gmehling, J. (2007). Measurement of vapor-liquid equilibria (VLE) and excess enthalpies (HE) of binary systems with 1-alkyl-3-methylimidazolium bis(trifluoromethylsulfonyl)imide and prediction of these properties and $\gamma^{\infty}$ using modified UNIFAC (Dortmund). Fluid Phase Equilib. 258, 168-178.

Pàmies, J. C. \& Vega, L. F. (2001). Vapor-liquid equilibria and critical behavior of heavy nalkanes using transferable parameters from the soft-SAFT equation of state. Ind. Eng. Chem. Res. 40, 2532-2543.

Pàmies, J.C. (2003). Bulk and interfacial properties of chain fluids. Ph.D. Thesis, Universitat Rovira i Virgili, Tarragona, Spain.

Raeissi, S. \& Peters C. J. (2009). Carbon Dioxide Solubility in the Homologous 1-Alkyl-3methylimidazolium Bis(trifluoromethylsulfonyl)imide Family. J. Chem. Eng. Data 54, 382-386.

Rey-Castro, C. \& Vega, L. F. (2006). Transport properties of the ionic liquid 1-ethyl-3 methylimidazolium chloride from equilibrium molecular dynamics simulation. The effect of temperature. J. Phys. Chem. B 110, 14426-14435.

Rey-Castro, C.; Tormo, A. L. \& Vega, L. F. (2007). Effect of the flexibility and the anion in the structural and transport properties of ethyl-methyl-imidazolium ionic liquids. Fluid Phase Equilib. 256, 62-69.

Seddon, K. R.; Stark, A. \& Torres, M. J. (2002). In Clean Solvents: alternative media for chemical reactions and processing; Abraham, M. A., Moens, L., Eds.; American Chemical Society: Washington DC Vol. 819; pp 34.

Shah, J.; Brennecke, J. \& Maginn, E. J. (2002). Thermodynamic properties of the ionic liquid 1-n-butyl-3-methylimidazolium hexafluorophosphate from Monte Carlo simulations. Green Chem. 4, 112-118.

Shah, J. K. \& Maginn, E. J. (2004). A Monte Carlo simulation study of the ionic liquid 1-nbutyl-3-methylimidazolium hexafluorophosphate: liquid structure, volumetric properties and infinite dilution solution thermodynamics of $\mathrm{CO}_{2}$. Fluid Phase Equilib. 222, 195-203.

Shah, J. \& Maginn, E. J. (2005). Monte Carlo simulations of gas solubility in the ionic liquid 1-n-butyl-3-methylimidazolium hexafluorophosphate. J. Phys. Chem. B 109, 1039510405.

Shim, Y.; Choi, M. Y. \& Kim, H. J. (2005). A molecular dynamics computer simulation study of room-temperature ionic liquids. I. Equilibrium solvation structure and free energetic. J. Chem. Phys. 122, 044510 (12 pages).

Stell, G.; Rasaiah, J. C.; Narang, H. (1974). Thermodynamic perturbation-theory for simple polar fluids. 2. Mol. Phys. 27, 1393-1414.

Tariq, M.; Serro, A. P.; Mata, J. L.; Saramago, B.; Esperança, J. M. S. S.; Canongia Lopes, J. N. \& Rebelo, L. P. N. (2010). High-temperature surface tension and density measurements of 1-alkyl-3-methylimidazolium bistriflamide ionic liquids. Fluid Phase Equilib. 294, 131-138. 
Temple, D.J. ; Henderson, P.B. ; Brzozowski, J.R. ; Pearlstein, R.M. \& Cheng, H. (2008). High Gas Storage Capacities for Ionic Liquids through Chemical Complexation. J. Am. Chem. Soc., 130, 400-401.

Twu, C.H.; Gubbins, K.E. and Gray, C.G. (1975). Excess Thermodynamic Properties for Liquid Mixtures of Non-Spherical Molecules. Molecular Physics, 29, 713-729.

Urahata, S. M. \& Ribeiro, M. C. C. (2005). Single particle dynamics in ionic liquids of 1-alkyl3-methylimidazolium cations. J. Chem. Phys. 122, 024511.

van der Waals, J. D. (1894). Thermodynamische Theorie der Kapillarität unter voraussetzung stetiger Dichteänderung. Zeitschrift fur Physikalische Chemie-Leipzig 13, 657-725.

van der Waals, J. D. (1976). The thermodynamic theory of capillarity under the hypothesis of a continuous density variation. Translated by J.S. Rowlinson. Journal of Statistical Physics 20, 197-244.

Vega, L. F. \& Blas, F. J. (2000). Tricritical phenomena in chainlike mixtures from a molecularbased equation of state. Fluid Phase Equilib. 171, 91-104.

Vega, L.F.; Llovell, F. \& Blas, F. J. (2009). Capturing the Solubility Minima of n-Alkanes in Water by Soft-SAFT. J. Phys. Chem. B 113, 7621-7630.

Vega, L.F.; Vilaseca, O.; Llovell, F. \& Andreu, J.S. (2010). Modeling ionic liquids and the solubility of gases in them: Recent advances and perspectives. Fluid Phase Equilib. 294, 15-30.

Verevkin, S. P.; Safarov, J; Bich, E.; Hassel, E. \& Heintz, A. (2005). Thermodynamic properties of mixtures containing ionic liquids: Vapor pressures and activity coefficients of n-alcohols and benzene in binary mixtures with 1-methyl-3-butylimidazolium bis(trifluoromethyl-sulfonyl) imide. Fluid Phase Equilib. 236, 222-228.

Vila, J.; Varela, L. M. \& Cabeza, O. (2007). Cation and anion sizes influence in the temperature dependence of the electrical conductivity in nine imidazolium based ionic liquids. Electrochim Acta 52, 7413-7417.

Vilaseca, O. \& Vega, L.F. (2010). Direct calculation of interfacial properties of fluids close to the critical region by a molecular-based equation of state. Fluid Phase Equilib. doi:10.1016/j.fluid.2010.09.018.

Wasserscheid, P. \& Keim, W. (2000). Ionic liquids-new "solution" for transition metal catalysis. Angew. Chem. Int. Ed. Engl. 39, 3772-3789.

Wasserscheid, P. \& Welton, T. (eds) (2003) Front Matter and Index, in Ionic Liquids in Synthesis, Wiley-VCH Verlag GmbH \& Co. KGaA, Weinheim, FRG. ISBN: 9783527305155.

Welton,T. (1999). Room-Temperature Ionic Liquids. Solvents for Synthesis and Catalysis. Chem. Rev. 99, 2071-2084.

Wertheim, M. S. (1984a) Fluids with Highly Directional Attractive Forces. 1. Statistical Thermodynamics. J. Stat. Phys. 35, 19-34.

Wertheim, M. S. (1984b).Fluids with Highly Directional Attractive Forces. 2. Thermodynamic Perturbation Theory and Integral Equations.J. Stat. Phys. 35, 35-47.

Wertheim, M. S. (1986a). Fluids with Highly Directional Attractive Forces. 3. Multiple Attraction Sites. J. Stat. Phys. 42, 459-476.

Wertheim, M. S. (1986b). Fluids with Highly Directional Attractive Forces. 4. Equilibrium Polymerization. J. Stat. Phys. 42, 477-492. 
Widegren, J. A.; Saurer, E. M.; Marsh, K. N. \& Magee, J. W. (2005). Electrolytic conductivity of four imidazolium-based room-temperature ionic liquids and the effect of a water impurity. J. Chem. Thermodyn. 37, 569-575.

Xiaoyan J. \& Adidharma H. (2009). Thermodynamic modeling of ionic liquid density with heterosegmented statistical associating fluid theory. Chem. Eng. Science 64, 19851992.

Xu, W.; Cooper, E. I. \& Angell, C. A. (2003). Ionic Liquids: Ion Mobilities, Glass Temperatures, and Fragilities. J. Phys. Chem. B 107, 6170-6178.

Yokozeki, A. \& Shiflett, M.B. (2007). Hydrogen purification using room-temperature ionic liquids. Apply. Energ. 84, 351-361.

Zhou, Z. B.; Matsumoto, H. \& Tatsumi, K. (2005). Structure and Properties of New Ionic Liquids Based on Alkyl- and Alkenyltrifluoroborates. ChemPhysChem 6, 1324-1332. 


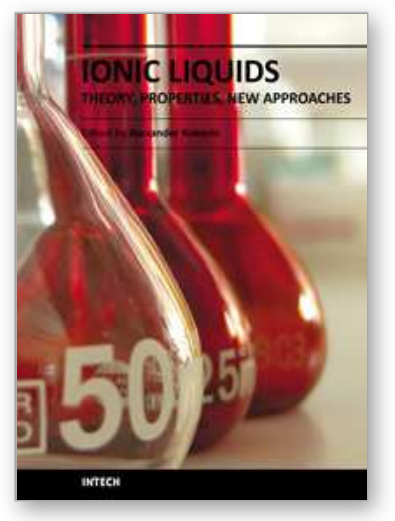

\section{Ionic Liquids: Theory, Properties, New Approaches}

Edited by Prof. Alexander Kokorin

ISBN 978-953-307-349-1

Hard cover, 738 pages

Publisher InTech

Published online 28, February, 2011

Published in print edition February, 2011

Ionic Liquids (ILs) are one of the most interesting and rapidly developing areas of modern physical chemistry, technologies and engineering. This book, consisting of 29 chapters gathered in 4 sections, reviews in detail and compiles information about some important physical-chemical properties of ILs and new practical approaches. This is the first book of a series of forthcoming publications on this field by this publisher. The first volume covers some aspects of synthesis, isolation, production, modification, the analysis methods and modeling to reveal the structures and properties of some room temperature ILs, as well as their new possible applications. The book will be of help to chemists, physicists, biologists, technologists and other experts in a variety of disciplines, both academic and industrial, as well as to students and PhD students. It may help to promote the progress in ILs development also.

\section{How to reference}

In order to correctly reference this scholarly work, feel free to copy and paste the following:

Lourdes F. Vega, Oriol Vilaseca, Edoardo Valente, Jordi S. Andreu, Fèlix Llovell, and Rosa M. Marcos (2011). Using Molecular Modelling Tools to Understand the Thermodynamic Behaviour of Ionic Liquids, Ionic Liquids: Theory, Properties, New Approaches, Prof. Alexander Kokorin (Ed.), ISBN: 978-953-307-349-1, InTech, Available from: http://www.intechopen.com/books/ionic-liquids-theory-properties-new-approaches/usingmolecular-modelling-tools-to-understand-the-thermodynamic-behaviour-of-ionic-liquids

\section{INTECH}

open science | open minds

\author{
InTech Europe \\ University Campus STeP Ri \\ Slavka Krautzeka 83/A \\ 51000 Rijeka, Croatia \\ Phone: +385 (51) 770447 \\ Fax: +385 (51) 686166 \\ www.intechopen.com
}

\author{
InTech China \\ Unit 405, Office Block, Hotel Equatorial Shanghai \\ No.65, Yan An Road (West), Shanghai, 200040, China \\ 中国上海市延安西路65号上海国际贵都大饭店办公楼 405 单元 \\ Phone: +86-21-62489820 \\ Fax: +86-21-62489821
}


(C) 2011 The Author(s). Licensee IntechOpen. This chapter is distributed under the terms of the Creative Commons Attribution-NonCommercialShareAlike-3.0 License, which permits use, distribution and reproduction for non-commercial purposes, provided the original is properly cited and derivative works building on this content are distributed under the same license. 